Luis Querol, MD, PhD

Ricard Rojas-García, MD, $\mathrm{PhD}$

Jordi Diaz-Manera, MD, $\mathrm{PhD}$

Joseba Barcena, MD

Julio Pardo, MD

Angel Ortega-Moreno, MD

Maria Jose Sedano, MD

Laia Seró-Ballesteros, MD

Alejandra Carvajal, MD

Nicolau Ortiz, MD, PhD

Eduard Gallardo, PhD

Isabel Illa, MD, PhD

Correspondence to

Prof. Illa:

iilla@santpau.cat

\section{Rituximab in treatment-resistant CIDP with antibodies against paranodal proteins}

\section{OPEN}

\section{ABSTRACT}

Objective: To describe the response to rituximab in patients with treatment-resistant chronic inflammatory demyelinating polyneuropathy (CIDP) with antibodies against paranodal proteins and correlate the response with autoantibody titers.

Methods: Patients with CIDP and IgG4 anti-contactin-1 (CNTN1) or anti-neurofascin-155 (NF155) antibodies who were resistant to IV immunoglobulin and corticosteroids were treated with rituximab and followed prospectively. Immunocytochemistry was used to detect anti-CNTN1 and anti-NF155 antibodies and ELISA with human recombinant CNTN1 and NF155 proteins was used to determine antibody titers.

Results: Two patients had a marked improvement; another patient improved slightly after 10 years of stable, severe disease; and the fourth patient had an ischemic stroke unrelated to treatment and was lost to follow-up. Autoantibodies decreased in all patients after rituximab treatment.

Conclusions: Rituximab treatment is an option for patients with CIDP with IgG4 anti-CNTN1/ NF155 antibodies who are resistant to conventional therapies.

Classification of evidence: This study provides Class IV evidence that rituximab is effective for patients with treatment-resistant CIDP with IgG4 anti-CNTN1 or anti-NF155 antibodies. Neurol Neuroimmunol Neuroinflamm 2015;2:e149; doi: 10.1212/NXI.0000000000000149

\section{GLOSSARY}

CIDP = chronic inflammatory demyelinating polyneuropathy; CNTN1 = contactin-1; IVIg = IV immunoglobulin; MuSK = muscle-specific tyrosine kinase; NF155 = neurofascin-155; ONLS = Overall Neuropathy Limitations Scale; PEx = plasma exchange; PLA2R = M-type phospholipase A2 receptor; R-ODS = Rasch-built Overall Disability Scale.

Chronic inflammatory demyelinating polyneuropathy (CIDP) is a heterogeneous autoimmune neuropathy. ${ }^{1}$ A subset of patients with CIDP with homogeneous phenotypic features have antibodies against node of Ranvier proteins, such as contactin-1 (CNTN1) and neurofascin155 (NF155). ${ }^{2-5}$ CNTN1 is a paranodal protein that is essential to organize the axo-glial junction and preserve node of Ranvier function. ${ }^{6}$ We previously reported that patients with antibodies against CNTN1 present with an aggressive neuropathy with a predominantly motor phenotype, axonal damage at onset, and, in contrast to most patients with CIDP, a poor response to IV immunoglobulin (IVIg). ${ }^{2}$ It is important that the anti-CNTN1 antibodies in these patients are of the IgG4 isotype, which preliminary pathologic reports ${ }^{7}$ and in vitro experiments suggest may be pathogenic. ${ }^{8}$ NF155 is the glial counterpart of CNTN1 and also plays an essential role in node of Ranvier structure and function. ${ }^{9}$ We have shown that

From the Neuromuscular Diseases Unit (L.Q., R.R.-G., J.D.-M., E.G., I.I.), Department of Neurology, Hospital de la Santa Creu i Sant Pau, Universitat Autònoma de Barcelona, Barcelona, Spain; Centro para la Investigación Biomédica en Red en Enfermedades Raras (L.Q., R.R.-G., J.D.-M., E.G., I.I.), CIBERER, Madrid, Spain; Neurology Department (J.B.), Hospital Universitario de Cruces, Universidad del País Vasco, Spain; Department of Neurology (J.P.), Hospital Clínico de Santiago, Santiago de Compostela, Spain; Department of Neurology (A.O.-M., A.C.), Hospital Virgen de las Nieves, Granada, Spain; Department of Neurology (M.J.S.), University Hospital "Marqués de Valdecilla" (IFIMAV) and University of Cantabria, Santander, Spain; Department of Neurology (L.S.-B.), Hospital Univeristari Vall d'Hebrón, Universitat Autònoma de Barcelona, Barcelona, Spain; and Department of Neurology (UHN) (N.O.), Hospital Universitari Sant Joan, Universitat Rovira i Virgili, Reus, Spain.

Funding information and disclosures are provided at the end of the article. Go to Neurology.org/nn for full disclosure forms. The Article Processing Charge was paid by Institut Recerca Sant Pau.

This is an open access article distributed under the terms of the Creative Commons Attribution-NonCommercial-NoDerivatives License 4.0 (CC BY-NC-ND), which permits downloading and sharing the work provided it is properly cited. The work cannot be changed in any way or used commercially. 
anti-NF155 antibodies are associated with a specific CIDP phenotype characterized by predominantly distal motor involvement and prominent intention tremor. The antibodies are also of the $\mathrm{IgG} 4$ isotype and these patients also have poor response to IVIg. ${ }^{3}$

Diseases mediated by antibodies of the IgG4 isotype, such as myasthenia gravis with anti-muscle-specific tyrosine kinase (MusK) antibodies, pemphigus vulgaris, and anti-Mtype phospholipase A2 receptor (PLA2R) idiopathic membranous nephropathy, respond well to B cell-depleting therapies. This response appears even in patients resistant to immunosuppressant drugs and is frequently associated with a profound and sustained depletion of autoantibodies. ${ }^{10-12}$ Considering this, our study aimed to evaluate the response to rituximab in the subset of patients with treatment-resistant CIDP with IgG4 anti-CNTN1 or anti-NF155 antibodies and to determine whether clinical response is associated with a change in autoantibody titer.

METHODS Patients and samples. We included all patients seen in our clinics and those from other Spanish centers meeting the European Federation of Neurological Societies/Peripheral Nerve Society task force diagnostic criteria ${ }^{13}$ for CIDP who harbored antibodies against either CNTN1 or NF155 and were resistant to IVIg and corticosteroids. Rituximab was offered to these patients as an off-label treatment following our institution's protocol for compassionate use of off-label drugs. Patients received $375 \mathrm{mg} / \mathrm{m}^{2}$ once weekly for 4 weeks followed by 1 dose per month for 2 additional doses. Additional rituximab cycles were administered 1 year after treatment in patients not achieving full recovery.

Clinical appointments and blood sampling were scheduled every 3 months during the first year and every 6 months thereafter. Overall Neuropathy Limitations Scale (ONLS) ${ }^{14}$ and Raschbuilt Overall Disability Scale (R-ODS) ${ }^{15}$ scores were collected prospectively.

Patients that remained significantly disabled (ONLS $\geq 5$ ) despite treatment with IVIg and corticosteroids were classified as treatment resistant.

Data were recorded in a coded database.

Standard protocol approvals, registrations, and patient consents. Informed consent for study participation was obtained from all patients under a protocol approved by the Ethics Committee of the Hospital de la Santa Creu i Sant Pau.

Anti-CNTN1 and anti-NF155 antibody detection and titration. Serum antibodies against CNTN1 or NF155 were detected by immunocytochemistry using human CNTN1- or NF155-transfected HEK293 cells, as previously described. ${ }^{2,3}$

ELISA was used for autoantibody isotype identification and titration, as previously described. ${ }^{3,8} \mathrm{~A}$ sample was considered positive when the optical density was higher than that of the average for healthy donors $(n=8)$ plus 4 SDs. All samples were tested simultaneously. To control for nonspecific IgG titer variation, all samples were also tested with VaccZyme ELISA (Binding Site,
Barcelona, Spain) for anti-tetanic toxoid antibodies, following the manufacturer instructions. Anti-tetanic antibody levels are presented in IU per $\mathrm{mL}$.

Classification of evidence. The primary objectives of our study were to describe the response to rituximab in patients with treatment-resistant CIDP with antibodies against paranodal proteins and to correlate the response with autoantibody titers. This study provides Class IV evidence that rituximab is effective for patients with treatment-resistant CIDP with IgG4 anti-CNTN1 or anti-NF155 antibodies.

RESULTS We identified 9 patients harboring antibodies against CNTN1 or NF155 meeting inclusion criteria. Four patients were from our clinics $(6.5 \%$ of all patients with CIDP) and 5 (of 32, 15.6\%) were from different Spanish centers in which antiCNTN1 or NF155 antibodies were suspected because the patients were either IVIg resistant or their clinical features matched patients that were previously described with these antibodies.

Of the 9 patients, 2 died (both anti-CNTN1+, patients 8 and 9), 1 had a complete response to corticosteroids (anti-CNTN1+, patient 7), and 6 were treatment resistant. One of these patients (patient 6 , anti-NF155+) was excluded because she had previously received rituximab for a marginal zone $\mathrm{B}$ cell lymphoma. Another patient (patient 5, antiNF155+) declined rituximab treatment. The 4 remaining patients ( 2 anti-CNTN1+, patients 1 and 4; 2 anti-NF155+, patients 2 and 3) were included in the study and treated with rituximab. The clinical features of these patients have been previously reported. ${ }^{2,3}$ Three of the patients improved after rituximab treatment in both R-ODS and ONLS scores. Patients 1 and 2 were both severely disabled and had substantial improvement that persisted at 1 year. Neither had responded to previous therapies except for a transient response to plasma exchange (PEx) that did not last longer than 2 months. Rituximab treatment was scheduled immediately after the last PEx course. Patient 1 improved dramatically after rituximab treatment and was able to be withdrawn from other treatments. He has resumed all previous activities (figure 1A) and has not relapsed to date (16 months after treatment). Patient 2 had substantial improvement with mild residual disability (predominantly distal leg weakness) (figure 1C). Disease duration in these 2 patients was less than 1 year at the initiation of rituximab. Patient 3 improved slightly (figure 1E). This patient had significantly longer disease duration (15 years) than patients 1 and 2 and an EMG showed features consistent with axonal degeneration. This patient did not receive PEx prior to rituximab as he had not responded to a prior PEx course after 3 successful PEx courses at disease onset. Patient 4 was removed from the study because she had a cardioembolic middle cerebral artery infarction soon after 
Figure 1 Clinical status and autoantibody titers in rituximab-treated patients with anti-CNTN1/NF155 chronic inflammatory demyelinating polyneuropathy

Clinical status

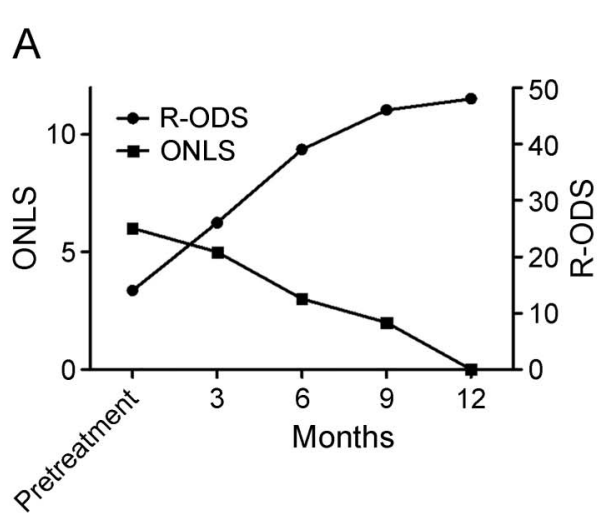

Autoantibodies

Patient 1

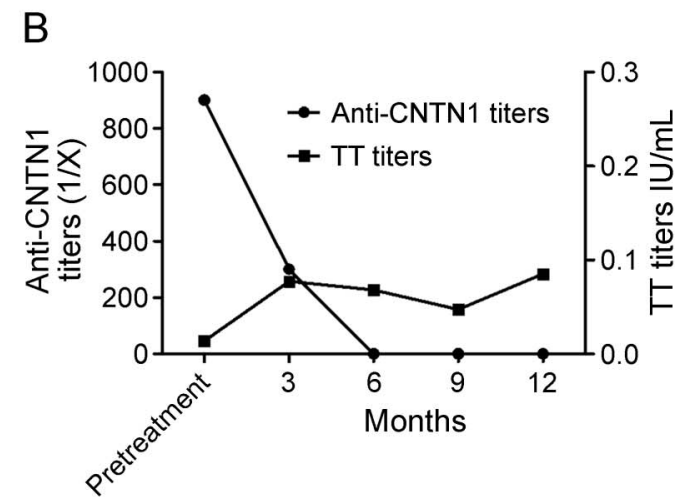

Patient 2
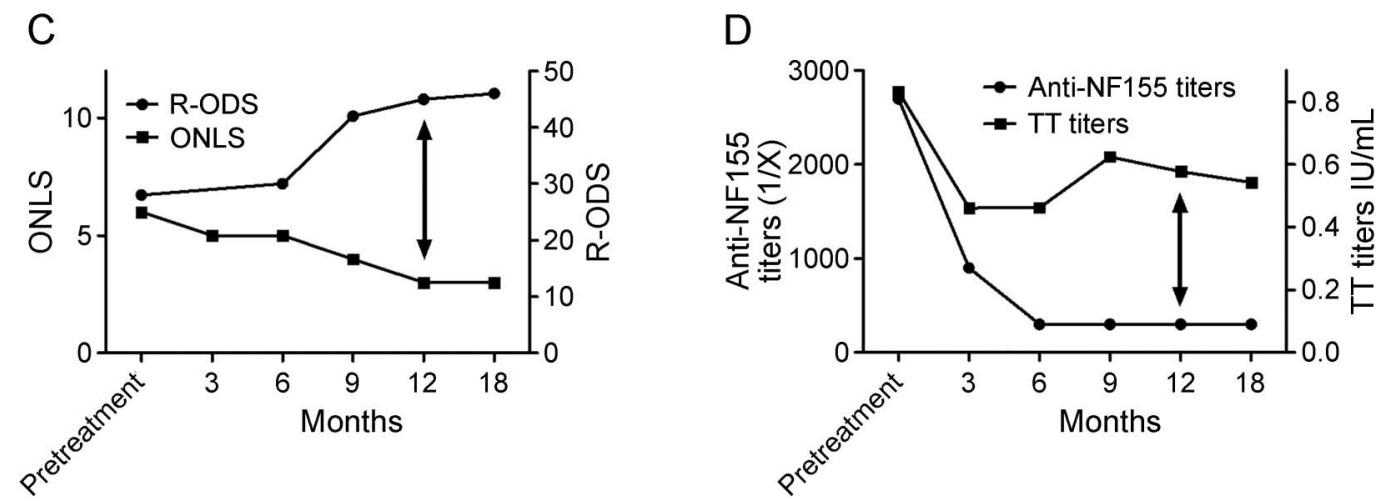

Patient 3
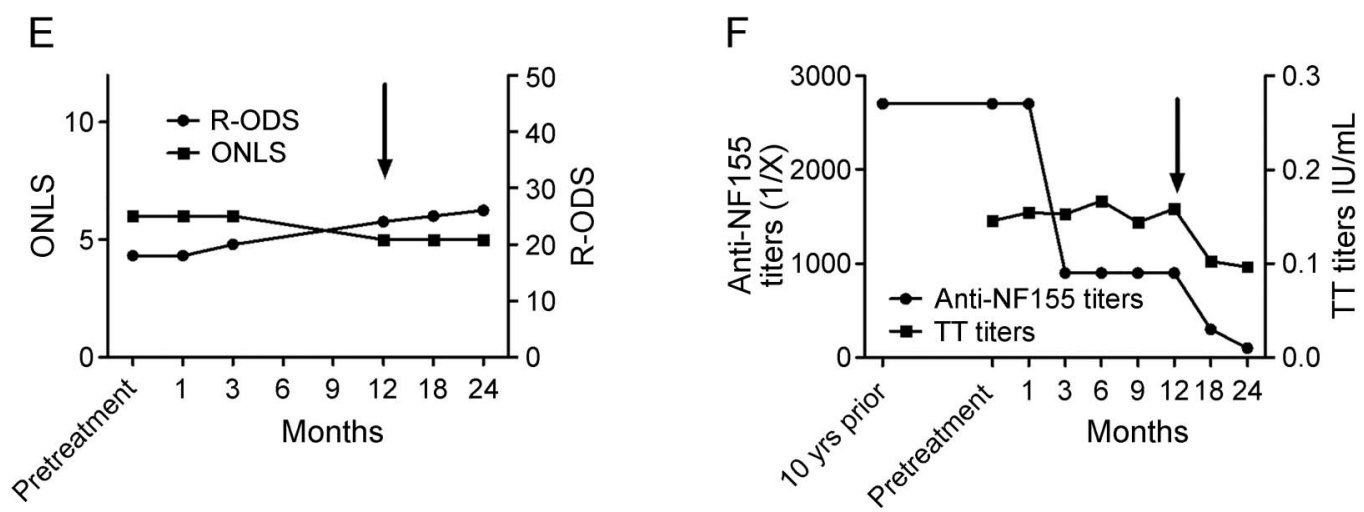

Patient 1 improved dramatically after rituximab treatment in both Rasch-built Overall Disability Scale (R-ODS) and Overall Neuropathy Limitations Scale (ONLS) scores, reaching full recovery at 12 months (A). Anti-contactin-1 (CNTN1) antibody titers decreased rapidly and were undetectable as early as 6 months after treatment, whereas anti-tetanic toxoid (TT) antibodies remained stable after treatment (B). Patient 2 had marked improvement after rituximab treatment in both R-ODS and ONLS scores, although mild leg distal weakness persisted (C). Anti-neurofascin-155 (NF155) antibody titers decreased rapidly and remained low 18 months after treatment. Anti-TT antibodies, however, decreased immediately after treatment and stabilized thereafter (D). Patient 3 improved slightly after rituximab treatment in both R-ODS and ONLS scores, although marked disability persisted (E). This patient had a significantly longer disease duration (more than 15 years) and secondary axonal damage. Nevertheless, anti-NF155 antibody titers decreased rapidly after treatment and stabilized at a titer of 1/900. An additional rituximab course further decreased anti-NF155 antibody titers. Anti-TT antibodies remained stable after treatment (F). Arrows represent additional rituximab courses.

the first rituximab dose that resulted in severe disability and institutionalization, precluding follow-up evaluations.
Anti-CNTN1 and anti-NF155 antibodies were predominantly of the IgG4 isotype in all 4 patients, as previously described. ${ }^{3,8}$ Anti-CNTN1 and anti-NF155 
Figure 2 Clinical and autoantibody status of 2 CNTN1 or NF155+ patients not receiving rituximab

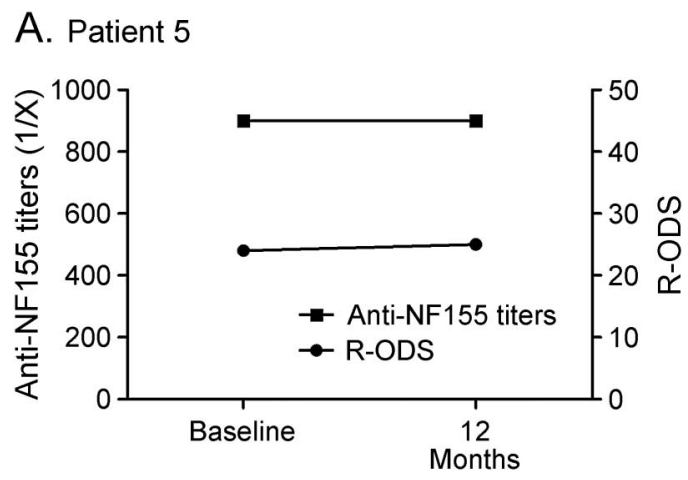

B. Patient 7

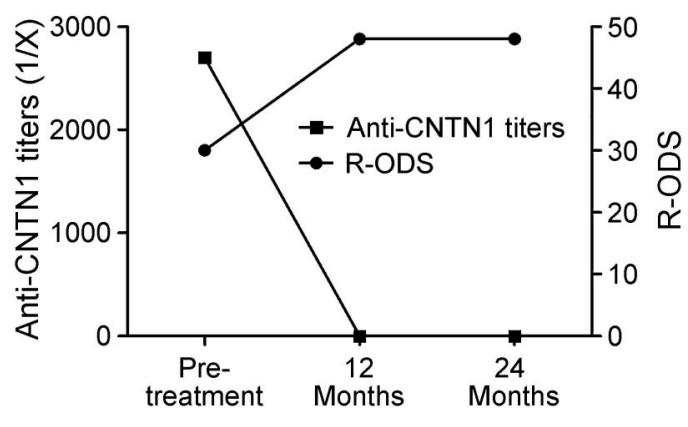

Despite corticosteroids and methotrexate treatment, patient 5 remained significantly disabled but declined to be treated with rituximab and his clinical status and autoantibody levels remained stable (A). Patient 7 is the only patient from our cohort fully responding to corticosteroids. Clinical scales improved clearly and anti-contactin1 (CNTN1) antibodies disappeared (B). NF155 = neurofascin-155; R-ODS = Rasch-built Overall Disability Scale.

IgG4 antibody titers decreased significantly in all patients after rituximab treatment. IgG4 autoantibody titers at 6 months were significantly lower or undetectable by ELISA compared with baseline in the rituximab-treated patients. In contrast, anti-tetanic toxoid autoantibodies remained stable or decreased slightly after rituximab treatment (figure 1, B, D, and F).

To investigate whether the decrease in autoantibody titers was related to treatment or to the normal evolution of a monophasic immune response, we performed the following studies. First, we tested antiNF155 antibodies in patient 3 from a serum sample extracted 10 years before rituximab treatment. Titers were similar to those at inclusion (figure $1 \mathrm{~F}$ ). Unfortunately, pretreatment autoantibody stability could not be tested in patients 1 and 2 (as in patient 3) because the only prerituximab samples available were the ones shown in figure 1 . Second, in patient 5 , who declined rituximab treatment, both autoantibody titers and clinical status measured by R-ODS remained stable after 1 year of follow-up despite treatment with corticosteroids and methotrexate (figure 2A). Finally, in the patient (patient 7) who met inclusion criteria but did not receive rituximab due to a complete response to corticosteroids, the clinical response was associated with a highly significant reduction of autoantibody titers after 1 year (figure 2B).

DISCUSSION Our study reinforces the diagnostic and therapeutic importance of identifying patients with CIDP harboring IgG4 anti-CNTN1/NF155. These antibodies are biomarkers of a subpopulation of patients with CIDP who are resistant to IVIg and steroids but who can have marked and even dramatic improvement with rituximab.

The high proportion of IVIg-resistant patients with anti-CNTN1 or anti-NF155 antibodies ${ }^{2,3,16}$ is in contrast to the high IVIg response rates seen in typical $\mathrm{CIDP}^{17}$ and led us to consider alternative treatments. Rituximab is associated with longlasting and profound responses in other IgG4mediated diseases, suggesting that it could be effective in patients with IgG4 anti-CNTN1/NF155 who are resistant to IVIg and corticosteroids. In our cohort, rituximab resulted in a dramatic response in $2 \mathrm{pa}-$ tients and a slight improvement in a third. The fact that disease duration was significantly shorter in the patients who had marked responses suggests that early treatment may be important in order to avoid permanent nerve damage. This hypothesis is supported by the fact that the 2 marked responders had also responded to PEx whereas patient 3, after 3 successful PEx cycles, had become PEx resistant. As response might vary depending on disease duration or axonal damage, early detection of these patients may have prognostic implications.

Some case reports and small case series describe CIDP improvement with rituximab, ${ }^{18}$ but there is limited evidence to recommend its systematic use. Despite the small number of patients, our study illustrates how the IgG4 isotype of the antibodies helped in therapy selection based on pathophysiologic homology with other diseases rather than CIDP-specific features. The recent report by Doppler et al. ${ }^{7}$ briefly describing 1 IgG4 anti-CNTN1+ patient who also responded to rituximab supports our findings.

Autoantibody titers decreased substantially in all patients treated with rituximab regardless of the degree of response, whereas antibodies against tetanic toxoid (mainly IgG1) remained stable. Autoantibody titers were also lowered substantially in the only patient from our series fully responding to corticosteroids. Of interest, a correlation between antibody titers and clinical status has also been found in patients with myasthenia gravis and antibodies to MuSK (IgG4 isotype) but not in patients with antibodies against acetylcholine receptor (IgG1-3 isotypes). ${ }^{11}$ This phenomenon seems to be $\operatorname{IgG}$ isotype-dependent, as it occurs in other 
IgG4-mediated diseases such as pemphigus vulgaris and anti-PLA2R idiopathic membranous nephropathy. ${ }^{10,19}$

CIDP is a rare disease and patients with IgG4 antiCNTN1/NF155 CIDP account for less than 10\% of all patients with CIDP. ${ }^{2,3,16}$ Thus the number of patients with CIDP and IgG4 antibodies is very small, which is the main limitation of our study. However, the magnitude and potential relevance of the findings in these few cases suggest that testing for these antibodies can have important therapeutic implications. Clinical and electrophysiologic diagnostic criteria are undoubtedly essential for detecting patients with inflammatory neuropathies so that treatment can be promptly initiated. However, the identification of specific biomarkers should be a research priority in a tissue-specific and heterogeneous disease such as CIDP. ${ }^{20}$ Infrequent antibodies may define small CIDP subtypes that, in aggregate, represent a relevant proportion of all patients with CIDP. Identifying novel clinical-immunologic associations will refine the diagnosis of CIDP, guide treatment selection, and help monitor response to treatment.

\section{AUTHOR CONTRIBUTIONS}

I.I. and L.Q. conceived, designed, and performed the experiments and wrote, edited, and revised the manuscript. L.Q., R.R.-G., E.G., and I.I. analyzed the data. All other authors provided characterized specimens.

\section{ACKNOWLDGEMENT}

The authors thank Fina Araque, Miquel Navas, Dana Assylbekova, and Roser Alba for technical support. The authors thank the patients and their families for their participation.

\section{STUDY FUNDING}

This study was funded by the Fondo de Investigaciones Sanitarias-Instituto de Salud Carlos III (13/937) to I.I. and 13/014 to L.Q., the European Research Area Network (ACAMIN project), and the GBS-CIDP Foundation. L.Q. is supported by the JR 13/00014 grant of the Fondo de Investigaciones Sanitarias-Instituto de Salud Carlos III.

\section{DISCLOSURE}

L. Querol received a travel grant from Bayer-Schering and research support from Fondo de Investigaciones Sanitarias, Subprograma Jual Rodes. R. Rojas-García serves on an advisory board for Pfizer. J. Diaz-Manera received speaker honoraria and a travel grant from Genzyme. J. Barcena, J. Pardo, A. Ortega-Moreno, M. Jose Sedano, L. Seró-Ballesteros, A. Carvajal, and N. Oritz report no disclosures. E. Gallardo holds a patent for blood-based assay for dysferlinopathies. I. Illa received a travel grant from Genzyme, is on the editorial board for Neurologia, holds a patent for dysferlin detection in monocytes, has consulted for Grifols, and received research support from Fondo de Investigaciones Sanitarias, ISCIII, Ministry of Health (Spain), Fundacion Gemio. Go to Neurology.org/nn for full disclosure forms.

Received May 18, 2015. Accepted in final form July 15, 2015.

\section{REFERENCES}

1. Mathey EK, Park SB, Hughes RA, et al. Chronic inflammatory demyelinating polyradiculoneuropathy: from pathology to phenotype. J Neurol Neurosurg Psychiatry Epub 2015 Feb 12. doi: 10.1136/jnnp-2014-309697.

2. Querol L, Nogales-Gadea G, Rojas-Garcia R, et al. Antibodies to contactin-1 in chronic inflammatory demyelinating polyneuropathy. Ann Neurol 2013;73: 370-380.

3. Querol L, Nogales-Gadea G, Rojas-Garcia R, et al. Neurofascin IgG4 antibodies in CIDP associate with disabling tremor and poor response to IVIg. Neurology 2014;82: 879-886.

4. Devaux JJ, Odaka M, Yuki N. Nodal proteins are target antigens in Guillain-Barré syndrome. J Peripher Nerv Syst 2012;17:62-71.

5. Man JK, Malotka J, Kawakami N, et al. Neurofascin as a target for autoantibodies in peripheral neuropathies. Neurology 2012;79:2241-2248.

6. Boyle ME, Berglund EO, Murai KK, Weber L, Peles E, Ranscht B. Contactin orchestrates assembly of the septatelike junctions at the paranode in myelinated peripheral nerve. Neuron 2001;30:385-397.

7. Doppler K, Appeltshauser L, Wilhelmi K, et al. Destruction of paranodal architecture in inflammatory neuropathy with anti-contactin-1 autoantibodies. J Neurol Neurosurg Psychiatry 2015;86:720-728. doi: 10.1136/jnnp-2014309916.

8. Labasque M, Hivert B, Nogales-Gadea G, Querol L, Illa I, Faivre-Sarrailh C. Specific contactin N-glycans are implicated in neurofascin binding and autoimmune targeting in peripheral neuropathies. J Biol Chem 2014;289:7907-7918.

9. Pillai AM, Thaxton C, Pribisko AL, Cheng JG, Dupree JL, Bhat MA. Spatiotemporal ablation of myelinating glia-specific neurofascin (Nfasc NF155) in mice reveals gradual loss of paranodal axoglial junctions and concomitant disorganization of axonal domains. J Neurosci Res 2009;87:1773-1793.

10. Joly P, Mouquet H, Roujeau JC, et al. A single cycle of rituximab for the treatment of severe pemphigus. $\mathrm{N}$ Engl J Med 2007;357:545-552.

11. Díaz-Manera J, Martínez-Hernández E, Querol L, et al. Long-lasting treatment effect of rituximab in MuSK myasthenia. Neurology 2012;78:189-193.

12. Khosroshahi A, Carruthers MN, Deshpande V, Unizony S, Bloch DB, Stone JH. Rituximab for the treatment of IgG4-related disease: lessons from 10 consecutive patients. Medicine (Baltimore) 2012;91:57-66.

13. Van den Bergh PY, Hadden RD, Bouche P, et al; European Federation of Neurological Societies, Peripheral Nerve Society. European Federation of Neurological Societies/Peripheral Nerve Society guideline on management of chronic inflammatory demyelinating polyradiculoneuropathy: report of a joint task force of the European Federation of Neurological Societies and the Peripheral Nerve Society—first revision. Eur J Neurol 2010;17:356-363.

14. Graham RC, Hughes RA. A modified peripheral neuropathy scale: the Overall Neuropathy Limitations Scale. J Neurol Neurosurg Psychiatry 2006;77:973-976.

15. Van Nes SI, Vanhoutte EK, van Doorn PA, et al. Rasch-built Overall Disability Scale (R-ODS) for immune-mediated peripheral neuropathies. Neurology 2011;76:337-345.

16. Miura Y, Devaux JJ, Fukami Y, et al. Contactin 1 IgG4 associates to chronic inflammatory demyelinating polyneuropathy with sensory ataxia. Brain 2015;138:1484-1491.

17. Hughes RA, Donofrio P, Bril V, et al; ICE Study Group. Intravenous immune globulin (10\% caprylatechromatography purified) for the treatment of chronic inflammatory demyelinating polyradiculoneuropathy (ICE study): a randomised placebo-controlled trial. Lancet Neurol 2008;7:136-144. 
18. Mahdi-Rogers M, van Doorn PA, Hughes RA. Immunomodulatory treatment other than corticosteroids, immunoglobulin and plasma exchange for chronic inflammatory demyelinating polyradiculoneuropathy. Cochrane Database Syst Rev 2013;6:CD003280.

19. Oh YJ, Yang SH, Kim DK, Kang SW, Kim YS. Autoantibodies against phospholipase A2 receptor in Korean patients with membranous nephropathy. PLoS One 2013;8:e62151.

20. Berger M, McCallus DE, Lin CS. Rapid and reversible responses to IVIG in autoimmune neuromuscular diseases suggest mechanisms of action involving competition with functionally important autoantibodies. J Peripher Nerv Syst 2013;18:275-296. 


\section{Neurology \\ Neuroimmunology \& Neuroinflammation}

\section{Rituximab in treatment-resistant CIDP with antibodies against paranodal proteins \\ Luis Querol, Ricard Rojas-García, Jordi Diaz-Manera, et al. \\ Neurol Neuroimmunol Neuroinflamm 2015;2; \\ DOI 10.1212/NXI.0000000000000149}

This information is current as of September 3, 2015

\section{Updated Information \& Services \\ Supplementary Material}

References

Citations

Subspecialty Collections

Permissions \& Licensing

Reprints including high resolution figures, can be found at: http://nn.neurology.org/content/2/5/e149.full.html

Supplementary material can be found at: http://nn.neurology.org/content/suppl/2015/10/31/2.5.e149.DC1

This article cites 19 articles, 3 of which you can access for free at: http://nn.neurology.org/content/2/5/e149.full.html\#\#ref-list-1

This article has been cited by 10 HighWire-hosted articles: http://nn.neurology.org/content/2/5/e149.full.html\#\#otherarticles

This article, along with others on similar topics, appears in the following collection(s):

Chronic inflammatory demyelinating polyneuropathy

http://nn.neurology.org//cgi/collection/chronic_inflammatory_demyeli nating_polyneuropathy

Class IV

http://nn.neurology.org//cgi/collection/class_iv

Information about reproducing this article in parts (figures,tables) or in its entirety can be found online at:

http://nn.neurology.org/misc/about.xhtml\#permissions

Information about ordering reprints can be found online: http://nn.neurology.org/misc/addir.xhtml\#reprintsus

Neurol Neuroimmunol Neuroinflamm is an official journal of the American Academy of Neurology.

Published since April 2014, it is an open-access, online-only, continuous publication journal. Copyright $\odot$ 2015 American Academy of Neurology. All rights reserved. Online ISSN: 2332-7812.

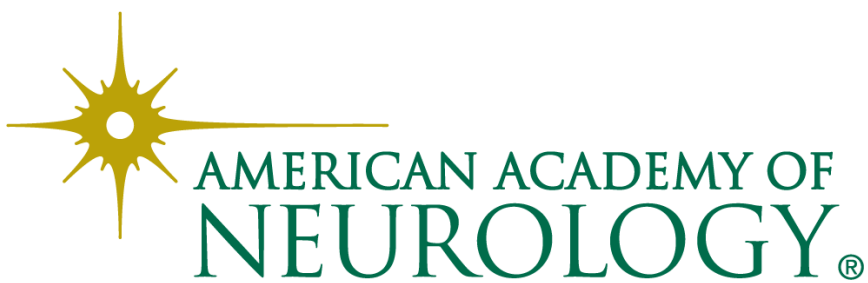

